\title{
A district framework for managing psychosocial aspects of disaster
}

\section{Mike Hobbs}

Natural disasters occur infrequently in Europe, but the spate of transportation, crowd and other disasters in the late 1980s challenged our collective denial of potential catastrophe. Greater attention is now given also to the frequent small-scale traumatic events which are just as devastating to the many people affected by them, such as violent assaults and road accidents.

Whatever their cause and scale, traumatic events have a significant and often lasting psychological impact. It would be unthinkable for health services to make no provision for managing the physical effects of destructive events, yet few mental health services are prepared for the psychiatric casualties of trauma. Those mental health professionals who have had to respond to disaster now argue in favour of comprehensive preparation for a psychosocial response.

\section{Causes of disaster}

A disaster is a large-scale destructive event which challenges and potentially overwhelms the personal and operational resources of the individuals, families, communities and services affected. Disasters may be sudden and unexpected (e.g. a plane crash), or insidious and prolonged (e.g. famine). The causes of disaster are often divided into natural or man-made (Box 1), although there are areas of overlap. In the technologically advanced world, the most common disasters are transportation incidents.

The task facing those who address the psychosocial impact of a disaster will be determined by its scale, including the size and geographical spread of the populations affected (Box 2). For example, the Hillsborough disaster was a large-scale national

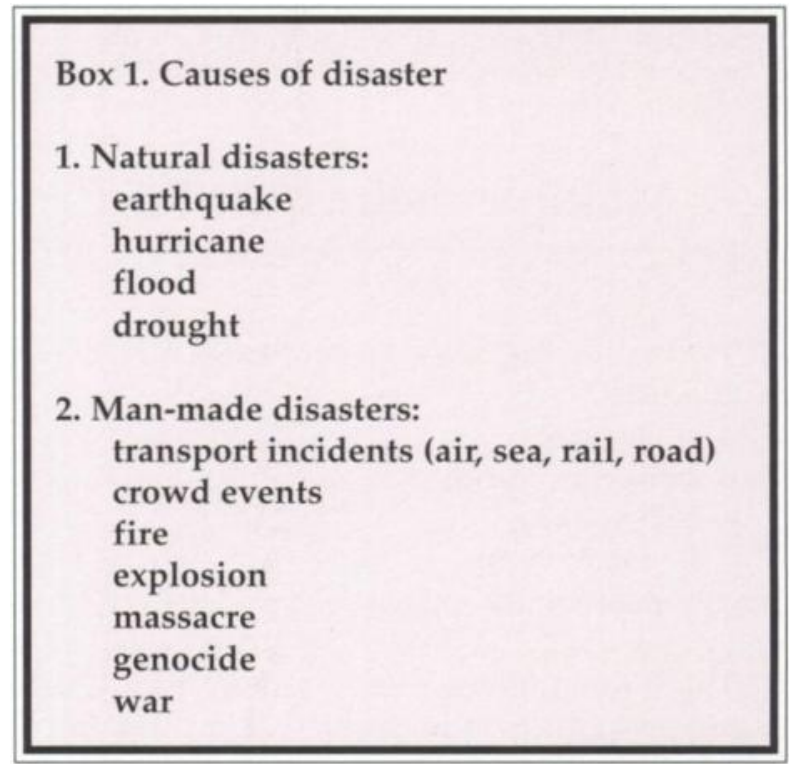

crowd disaster ( 95 deaths and many injured) which affected two close-knit and geographically separate communities; whereas the Lockerbie jumbo jet explosion was a large-scale international disaster, involving the deaths of 270 people of 33 nationalities, including eleven residents of the small Scottish town onto which the wreckage fell.






\section{Psychological victims of disaster}

The psychological effects of trauma are 'contagious'. By a powerful mental ripple effect, disaster has an impact on people at progressively greater geographical and temporal distances from the incident (Box 3). At the epicentre are the primary victims, the injured and uninjured survivors; at one remove are their families and friends. The 'hidden victims' are those whose jobs bring them into contact with the physical and emotional suffering of the primary and secondary victims. They include emergency services personnel (Shepherd \& Hodgkinson, 1990; Moran \& Britton, 1994), frontline hospital staff, and the mental health staff who support and treat the traumatised (Hodgkinson \& Shepherd, 1994).

A significant proportion of each of these populations will be traumatised by the experience and will later develop psychiatric disorder.

Box 3. Psychological victims of disaster

Disaster victims:

Survivors of the incident, both injured and uninjured

Onlookers

Relatives and friends of the primary victims, including the bereaved

'Victims by proxy': those with a particular identification with the primary victims, including those who 'might have been there'

Those who feel responsible for the disaster, whether justifiably or not

Disaster workers:

Emergency service and other rescue workers Emergency medical teams

Body handlers and body identification teams

Front-line hospital staff, including accident department, X-ray and theatre staff

Other hospital staff, including ITU and trauma ward staff, mortuary attendants, bereavement officers, receptionists, porters, telephonists and managers

Media personnel

Carers and counsellors, including volunteers and mental health workers: those who support and treat the survivors, bereaved and others traumatised by the disaster, and thereby share the horror of it
The numbers of people affected and requiring psychological help in each category will vary according to the nature, scale and complexity of the destructive event. For example, there were no survivors of the aeroplane which exploded over Lockerbie so, although there were a few injured survivors in the town, the ambulance service and local hospitals were not stretched; but there was an extensive operation to support the bereaved relatives and traumatised townspeople.

\section{Psychosocial impact of disaster}

The psychological impact of traumatic events results from the interaction between (1) the nature of the event, (2) the state of the individual's inner world, and (3) the quality of the social context or 'recovery environment'.

\section{The nature of the event}

Many aspects of a traumatic event will influence its psychological impact, but particularly whether the victim faces death or witnesses the suffering, mutilation or death of others, especially loved ones. The traumatic impact is related to the perceived level of threat rather than the objective danger (Malt \& Olafsen, 1992).

Terr (1991) differentiated two categories of trauma, the characteristic reactions to which differ in significant ways. Type I trauma is the product of a single, intense, unanticipated event, such as an assault or crash. The characteristic psychological reaction includes repeated, intrusive recollections of the event, often alternating with avoidant behaviours (i.e. the pattern of PTSD). Type II trauma results from prolonged terrifying ordeals, perhaps repeated and thereby anticipated with dread, such as repeated violent sexual abuse in childhood, or torture. The psychological reaction is characterised by psychic numbing, dissociation, alternating rage and passivity, and may progress to pervasive personality deterioration. Crossover type I/II conditions occur when a single traumatic event results in prolonged adversity (e.g. accidental injury followed by severe disfigurement).

\section{The person's inner world}

People vary greatly in the ways they perceive and react to traumatic events. Everybody faces adversity 
at intervals, and the development of effective coping resources and a resilient personality depends on the constructive resolution of successive life crises. To some extent, a person's response to challenge will be influenced by the ways in which they were helped to cope with fear and pain in early life, by parents and other attachment figures.

Whereas the successful negotiation of earlier adversities generates self-confidence and a repertoire of coping skills, maladaptive solutions or a history of psychiatric breakdown in the face of crisis will leave the individual vulnerable to later challenges, including traumatic events. People with a history of psychiatric illness are more likely to develop post-traumatic psychopathology (Malt \& Olafsen, 1992; Blanchard et al, 1995). The screening of disaster victims might make it possible to offer a preventive psychological intervention to those identified as particularly vulnerable.

There is also an idiosyncratic dimension to trauma vulnerability, as present life circumstances or past adverse experience may render the person susceptible to specific aspects of an incident. One person may be traumatised by an event which merely upsets another. For example a woman who was trapped alone in a lift, in darkness, later recognised that her terror and subsequent PTSD were mediated in part by unconscious memories of being beaten and locked in a cupboard during childhood by her vindictive mother.

\section{Social context}

The individual's capacity to come to terms with a traumatic experience is greatly influenced by his or her social context. Secure, supportive relationships are essential for the victim's communication and processing of the traumatic experience, and eventual recovery. In psychodynamic terms this opportunity replicates the containing function of the early infant-mother relationship in which the child gradually learns to contain, process and tolerate fear and other powerful emotions (Garland, 1991). Those who had or have no close and emotionally containing relationships are more vulnerable to posttraumatic psychopathology; again, this suggests that psychosocial resources could be targeted after disasters at those who are identified as socially isolated. This population will include some people with severe mental illness, who are doubly vulnerable.

Even for those fortunate enough to have loving relationships, trauma is destructive to social and emotional ties. The social impact of disaster may derive from the destruction of the community of which the individual was a part, or from the destruction of the family by multiple bereavements.
The effect may be more insidious, however, for traumatic experience is inherently destructive to affectional bonds at the deepest level, obliterating any sense of safety, security and human relatedness. At best, the tolerance of relatives and friends may be tested by the victim's volatile emotions and need to recount the traumatic experience again and again, perhaps in graphic detail. At worst, the victim of trauma withdraws emotionally from even those closest to him, rejects love, and provokes the eventual breakdown of marriage or family. The victim's family should be involved, therefore, in the early preventive psychosocial intervention.

\section{Psychiatric reactions to disaster}

It is normal for people involved in traumatic incidents to experience an intense psychological reaction. Prior to and during the impact, particularly if there is a percieved risk of death, intense fear is natural; distress, anxiety and repeated recollections of the event are common in the early weeks. However, terror may generate a powerful stress reaction with a resultant inability to comprehend or adjust to the experience. Acute stress reactions are characterised by dissociation, disorientation, repeated sensory recollections of the experience, associated physiological arousal, and phobic avoidance (e.g. of the site, or mention of the event). With appropriate support, these symptoms may diminish over the ensuing weeks. Clinical and research evidence suggests, however, that early horrific memories and disabling symptoms are predictive of continuing psychopathology (Mayou et al, 1993; Koopmanet al, 1995). Persisting intrusive recollections, intense arousal and patterns of avoidance are diagnostic of post-traumatic stress disorder.

The effects of traumatic experience on children have often been overlooked. Younger children may display non-specific symptoms, and older children may attempt to disguise their own feelings if their parents are manifestly distressed or emotionally unavailable. Insomnia, anxiety, and regressive behaviours are common early symptoms. Later symptoms include sleep disturbance and nightmares, persisting separation anxiety, hyperactivity, and reenactment of the trauma through play (Raphael, 1986; Yule, 1991). In addition, children can display all the symptoms of PTSD.

The onset of post-traumatic stress reactions may be immediate or delayed by weeks, months or years. The emergence of frank psychiatric disorder may 
Box 4. Psychiatric disorders following disaster

Acute stress reaction (ICD-10); acute stress disorder (DSM-IV).

Phobic anxiety

Depression

Post-traumatic stress disorder (PTSD) (ICD10; DSM-IV)

Enduring personality change after catastrophic experience (ICD-10)

be triggered by later stressful events which, of themselves, appear relatively minor but which reactivate the residues of earlier traumatic experience. For example, an increasing number of Second World War veterans are presenting with post-traumatic symptoms derived from their horrific wartime experiences, and the triggers seem to be the involution and loss inevitable in those of now advancing age. Unless they experience explicit intrusive symptomatology, those who present with delayed-onset PTSD may not relate their disorder to the earlier trauma.

After mass disasters, victims may be expected to seek help in significant numbers for at least two to three years. The demand for psychiatric and related services often increases at the time of anniversaries, inquests, court hearings, and other public reminders of the tragedy.

Personality disorders may develop insidiously over the months and years following complex or prolonged (Type II) trauma, sometimes without an interim phase of PTSD. Irritability, explosiveness and avoidant behaviours destroy relationships. Substance misuse is common, and can be seen as an attempt to affect regulation. Post-traumatic personality disorders are associated with a significant mortality from risk-taking behaviours, suicide and homicide.

\section{Epidemiology}

Disasters have a major psychosocial impact. Hodgkinson \& Stewart (1991) calculated that more than 10000 people were affected psychologically by the capsize of the ferry Herald of Free Enterprise in Zeebrugge harbour in 1987.

Most $(70-80 \%)$ of those affected by disaster experience a powerful early psychological reaction: $30-40 \%$ develop post-traumatic psychopathology,
10-12\% manifesting the full diagnostic picture of PTSD (Raphael, 1986). The incidence of posttraumatic disorders following smaller scale traumatic events is similar (Mayou et al, 1993; Norris, 1992). Road accidents constitute an unacknowledged disaster in physical and psychiatric terms.

\section{Prevention}

\section{Preparation}

Effective preparation for very stressful experiences may diminish the incidence of subsequent psychiatric complications (Alexander \& Wells, 1991). This is of particular importance for emergency service and other rescue personnel who are inevitably exposed to highly stressful incidents during the course of their work, particularly following disaster.

\section{Psychological interventions}

Clinical evidence suggests that the survivors and other victims of disaster may be helped to come to terms with their traumatic experience if provided with early psychological first-aid designed to promote adaptive coping (Raphael, 1986; Parkes, 1991). There is no unequivocal scientific evidence yet for the effectiveness of psychological debriefing as a preventive measure (Yule, 1992; Stallard \& Law, 1993; Bisson \& Deahl, 1994; Deahl et al, 1994), but such interventions are generally welcomed by those who participate in them (Brom et al, 1993).

\section{Principles of psychosocial intervention}

\section{Disaster victims}

The majority of those affected psychologically by a disaster will be helped by the early provision of (a) kindness, support and common sense, (b) information about what happened to themselves and others involved in the incident, and what will happen at each subsequent stage, and (c) an opportunity to talk and express their feelings about the experience. This essential support may be provided first, during the course of rescue and immediate treatment, by emergency services personnel, trained members of key voluntary 
organisations (e.g. Red Cross, St John's Ambulance, WRVS) or front-line hospital staff.

Beyond the immediacy of the disaster, both in hospitals and the community, social workers and other professional or voluntary staff (e.g. primary health and community health staff, churches, and counselling agencies) play significant roles in meeting the psychosocial needs of the survivors, their relatives, and others. However, the majority of those affected by the incident will cope on their own with the help of family and friends.

The specific psychological needs of disaster victims are best met by the intervention of professional mental health staff with established competence in trauma psychology. Early specialised tasks include psychological triage at forward receiving stations and hospital accident departments for uninjured and injured survivors respectively; the mental state assessment and immediate psychiatric management of individuals causing concern, including those with acute stress reactions; and the identification and continuing support of individuals who, by virtue of specific vulnerability factors or severe early reactions, are at particular risk of later psychiatric morbidity. Those who go on to develop post-traumatic psychiatric disorders will require skilled diagnosis and treatment, psychological and sometimes psychopharmacological.

\section{Disaster workers}

The emergency and hospital accident services tend to adopt defensive cultures in relation to occupational stress, but their staff do experience traumatic stress when working with the victims of disaster and when exposed to more direct dangers. Professional workers require support following disasters just as much as the primary victims.

Post-incident support is usually undertaken by appropriately trained staff in two phases. Short initial defusing sessions are conducted after standing down for groups of staff who had a common experience of the incident. The aim of the defusing session is to afford an initial opportunity for emotional expression, to promote mutual support between members of the group, and to provide basic information about the identification and management of early psychological reactions to traumatic stress.

The preventive task is continued with one or more debriefing sessions, ideally held 24-72 hours after the incident and repeated two or three times at increasing intervals if necessary and feasible. Conducted by trained mental health staff, preferably with selected members of the service itself, the aim of psychological debriefing is to promote adaptive emotional and cognitive processing of the traumatic experience, and continued mutual support. The debriefing session also enables the mental health staff to identify those staff most at risk of developing post-traumatic disorders.

\section{Strategic planning}

Department of Health directives HSG(93)24 and EL(93)38 (Department of Health, 1993) require health authorities to contract with provider units to develop and maintain plans for managing major incidents, working with county councils and other agencies to ensure a coordinated response. The Department also identifies the requirement for adjacent provider units to cooperate in ensuring a 'seamless' response in the event of a major incident affecting the populations of adjacent authorities. There is also a compelling case for a national protocol because, not uncommonly, as in the case of the Hillsborough football stadium disaster, a major incident affects the populations of geographically separated districts.

Limited reference is made in the Department's directives to the psychosocial component of major incident response, but health authorities are advised to provide 'counselling' for survivors, relatives and staff; the guidance makes clear that this may need to continue 'over a prolonged period' (HC(90)25; Department of Health, 1990).

In addition, the Department has sponsored two professional reviews of planning for the psychosocial response to disaster, neither of which it has since authorised or acted upon (Disasters Working Party, 1991; Institute of Psychiatry, 1993). Their fundamental support for anticipatory planning was consistent with the recommendations of the British Psychological Society (1990) and those psychiatrists who have been faced with the psychosocial demands of a disaster (Burns \& Hollins, 1991; Parkes, 1991; Rosser et al, 1991).

Strategic provision should be made, therefore, for a district-wide psychosocial response and for crossdistrict cooperation when required. There may be advantages in a cross-district consortium of providers for some specialised components of the psychosocial response.

In view of the statutory responsibility of local authorities for emergency planning, it is sometimes suggested (Disasters Working Party, 1991) that social services should take lead responsibility for planning and coordinating the psychosocial response in the event of a disaster. This may be appropriate in some areas, but joint planning and coordination (as described below) has obvious advantages for inter-agency response. 


\section{District response framework}

Before disaster strikes, a plan should be agreed in each district which will enable a flexible psychosocial response to a range of possible disasters (Parkes, 1991; Gibson, 1994).

Adverse psychological and social reactions to disaster are interrelated, and should be managed jointly. To be effective, the psychosocial response following disaster needs to be comprehensive and integrated. Health service providers will need to work closely with social services, primary care and community health services, voluntary organisations and other relevant agencies. Joint planning, preparation and training can reduce the potential for inter-agency and inter-professional rivalry which is so common and destructive after disasters. Health and social services should determine locally how lead responsibilities should be allocated.

The psychosocial response must be feasible, immediate and proactive if it is to provide effective support and preventive interventions for the victims of the disaster. It is imperative that the response services are prepared for action and that the strategic plan can be put into operation without delay.

It is important, however, that the disaster response framework is integral to local mental health services. The psychosocial response should draw on established services and existing good practice. Where possible, the response might draw on the expertise of an existing traumatic stress service; it has been suggested that specialised trauma services should be established in each region (Institute of Psychiatry, 1993).

In preparing for disaster, provision must be made for the rapid establishment of a telephone helpline that can be publicised by local and national media. It is also helpful to distribute an information and advice leaflet to those involved in the disaster, outlining common symptomatic reactions to trauma, how to manage them, and when/how to seek professional help. A template for the leaflet can be prepared in advance, with details specific to the incident being incorporated before printing.

In the event of a disaster, resources may need to be made available for cascade training and deployment of additional staff, either to meet the psychosocial demands of the incident or to maintain the routine work of those staff who are assigned to post-disaster duties. Extra funding will be needed immediately, and the fundholders will need to be educated about the potential psychosocial needs of different populations at successive stages after the incident. Both organisational arrangements and funding will need to be geared to the maintenance of the psychosocial response over a prolonged period.

At the appropriate time, the formal response must be concluded decisively.

\section{Psychosocial response network}

One model of preparation for disaster, which has been adopted in differing ways by a growing number of health districts and local authorities, is to establish a network of selected, trained professional and voluntary staff which can be activated and expanded rapidly in the event of a disaster. The psychosocial response network is organised, and in the event of a major incident is mobilised, by a small coordinating group composed of senior practitioners from mental health and social services. This group is responsible for liaising closely with relevant agencies, including general hospitals, emergency services, and both statutory and voluntary community services, representatives of which may be coopted for specific tasks.

In the event of a major incident, the coordinating group can be alerted by ambulance control, by the general hospital's major incident procedure, or by the county council's emergency procedure. Action sheets detailing the expected psychosocial response need to be incorporated into both hospital and county major incident plans.

The psychosocial response network may comprise a number of discrete multidisciplinary core units, organised both on a locality basis and by specialist function. These can be activated by the coodinating group in varying permutations according to the location, scale and nature of the incident and the developing needs of its victims over time.

Box 5. Before disaster strikes: practical preparation

Inter-agency networking

Define roles and responsibilities

Rehearsal

Action sheets

Telephone helpline

Leaflet template

Prepare for cascade training

Identify funding 
Specialised units are established centrally, and deployed when necessary to back up the locality units' response to victim groups which have specific psychosocial requirements, such as children and their families; the elderly; hospitalised survivors and their relatives; and those victims who require long-term or specialised psychological/ psychiatric treatment.

Other specialised units are drawn from psychological treatment and related services for the support of front-line staff in the general hospital and support of emergency services personnel; central liaison with voluntary organisations and the coordination of volunteer counsellors (who, if carefully selected and supervised, represent a valuable resource); and training.

Staff should be selected, trained and supervised for trauma work. Selection criteria might include psychological hardiness, adaptive personal coping resources, professional experience of crisis intervention, and the absence of recent or unresolved personal loss or trauma. Basic training includes instruction in the realities of major incidents, the psychology of post-traumatic stress reactions, the social impact of trauma, relevant organisational processes, and the essentials of crisis intervention following destructive incidents. Joint training promotes interagency cooperation and team cohesion. Additional training is required to develop debriefing and other specific intervention skills. Supervision should be integral to the work of the core units to maximise effectiveness and to protect staff from the destructive effects of trauma work.

In order to ensure organisational readiness for disaster response, the psychosocial response network needs to rehearse the management of major incidents at regular intervals, and should participate in the full-scale major incident exercises organised at intervals by the county council and emergency services. The professional readiness and competence of staff is best maintained by ongoing clinical work with the victims of small-scale incidents such as road accidents, for whom no systematic psychosocial provision has been made hitherto in most districts.

One way of establishing functional inter-agency liaison in advance of any major incident is for mental health and social services staff to organise relevant training seminars. For example, working relationships with the staff of the accident department and trauma wards may be developed through a series of seminars in the general hospital on recognising and managing traumatic stress in their patients and themselves.

Such training activities can lead on to the creation of systems for staff support in the emergency services, front-line hospital departments and other agencies. Psychosocial response network members may contribute to team support and debriefing after critical incidents, even if other components of the psychosocial plan are not activated. In these ways, mental health staff become known and accepted in the very places and services to which they will need ready access in the event of a disaster.

In the event of a disaster, the core units of the network are supplemented by the rapid recruitment and cascade training of additional staff. This expansion is easier if all relevant mental health and social services staff have received basic teaching in trauma psychology.

An effective psychosocial response in the chaotic aftermath of disaster requires that the specific responsibilities of each contributing agency are defined, agreed and understood by all relevant organisations. Clear lines of authority and communication will be required, as will continuing liaison with the general hospital, community agencies and other relevant organisations.

\section{Conclusions}

In the present organisational context of the Health Service, there must be a contractual basis for service provision even in the aftermath of disaster. A planned psychosocial response should be authorised by the purchasing authorities and written into provider contracts. The prices set by provider units may include the cost of maintaining readiness for the psychosocial effects of disaster, and it should be remembered that small-scale disasters occur at intervals in all districts. The apparent cost of planning can be justified, however, if improved provision is made thereby for the victims of the daily personal disasters with which health workers are so familiar.

\section{References}

Alexander, D. A. \& Wells, A. (1991) Reactions of police officers to body-handling after a major disaster: before and after comparison. British Journal of Psychiatry, 159, 547-555.

Bisson, J. I. \& Deahl, M. P. (1994) Psychological debriefing and prevention of post-traumatic stress: more research is needed. British Journal of Psychiatry, 165, 717-720.

Blanchard, E. B., Hickling, E. J., Taylor, A. E., et al (1995) Psychiatric morbidity associated with motor vehicle accidents. Journal of Neroous and Mental Diseases (in press).

British Psychological Society (1990) Psychological Aspects of Disaster. Leicester: British Psychological Society. 
Brom, D., Kleber, R. J. \& Hofman, M. C. (1993) Victims of traffic accidents: incidence and prevention of post-traumatic stress disorder. Journal of Clinical Psychology, 49, 131-139.

Burns, T. P. \& Hollins, S. C. (1991) Psychiatric response to the Clapham rail crash. Journal of the Royal Society of Medicine, 84, 15-19.

Deahl, M. P., Gillham, A. B., Thomas, J., et al (1994) Psychological sequelae following the Gulf War: factors associated with subsequent morbidity and the effectiveness of psychological debriefing. British Journal of Psychiatry, 165, 60-65.

Department of Health (1990) Emergency planning in the NHS: Health Service arrangements for dealing with major incidents (HSG(93)24; EL(93)38).

(1993) Emergency planning in the NHS: Health Service arrangements for dealing with major incidents (HC(90)25).

Disasters Working Party (1991) Disasters: Planning for a Caring Response. London: HMSO.

Garland, C. (1991) External disasters and the internal world: an approach to psychotherapeutic understanding of survivors. In Textbook of Psychotherapy in Psychiatric Practice (ed. J. Holmes), pp. 507-532. Edinburgh: ChurchillLivingstone.

Gibson, M. (1994) Managing people's social and psychological needs after a disaster: experiences from Belfast and the M1 plane crash. In Management of Disasters and their Aftermath (eds W. A. Wallace, J. M. Rowles \& C. L. Colton), pp. 132145. London: BMJ Publishing Group.

Hodgkinson, P. E. \& Stewart, M. (1991) Coping with Catastrophe: a Handbook of Disaster Management. London: Routledge.

— \& Shepherd, M. A. (1994) The impact of disaster support work. Journal of Traumatic Stress, 7, 587-600.

Institute of Psychiatry (1993) Current Provision and Recommendations for the Management of Psychosocial Morbidity Following Disaster in England. London: Institute of Psychiatry.

Koopman, C., Classen, C., Cardena, E., et al (1995) When disaster strikes, acute stress disorder may follow. Journal of Traumatic Stress, 8, 29-46.

Malt, U. F. \& Olafsen, O. M. (1992) Psychological appraisal and emotional response to physical injury: a clinical, phenomenological study of 109 adults. Psychiatric Medicine, 10, 117134

Mayou, R., Bryant, B. \& Duthie, R. (1993) Psychiatric consequences of road traffic accidents. British Medical Journal, 307, 647-651.

Moran, C. \& Britton, N. R. (1994) Emergency work experience and reactions to traumatic incidents. Journal of Traumatic Stress, 7, 575-585

Norris, F. H. (1992) Epidemiology of trauma: frequency and impact of different potentially traumatic events on different demographic groups. Journal of Consulting and Clinical Psychology, 60, 409-418.

Parkes, C. M. (1991) Planning for the aftermath. Journal of the Royal Society of Medicine, 84, 22-25.

Raphael, B. (1986) When Disaster Strikes: a Handbook for the Caring Professions. London: Unwin Hyman.

Rosser, R., Dewar, S. \& Thompson, J. (1991) Psychological aftermath of the King's Cross fire. Journal of the Royal Society of Medicine, 84, 4-8.

Shepherd, M. \& Hodgkinson, P. (1990) The hidden victims of disaster: helper stress. Stress Medicine, 6, 29-35.

Stallard, P. \& Law, F. (1993) Screening and psychological debriefing of adolescent survivors of life-threatening events. British Journal of Psychiatry, 163, 660-665.

Terr, L. C. (1991) Childhood traumas: an outline and overview. American Journal of Psychiatry, 148, 10-20.

Yule, W. (1991) Children in shipping disasters. Journal of the Royal Society of Medicine, 84, 12-15.

(1992) Post-traumatic stress disorder in child survivors of shipping disasters: the sinking of the "Jupiter". Journal of Psychotherapy and Psychosomatics, 57, 200-205.

\section{Multiple choice questions}

1 Psychiatric reactions in disaster victims include: a depression

b hypomania

c phobic anxiety

d post-traumatic stress disorder

e personality disorder

2 Psychological vulnerability to trauma is heightened by:
a post-traumatic amnesia
b recent bereavement
c pre-existing psychiatric illness
d a strong social network
e physical injury

3 The Department of Health's guidance to health authorities for major incident planning includes requirements for:

a social services to take lead responsibility

b contracts with providers for major incident response

c counselling resources for survivors and staff

d seamless protective clothing for psychiatrists

e establishment of cross-district consortia of psychiatric services

4 The aims of psychological debriefing include:

a encouragement of emotional expression

b promotion of mutual peer support within the team

c review of team's operational performance

d initial group therapy for distressed staff

e promotion of emotional and cognitive adjustment

5 Psychosocial response after a disaster should be:

a led by psychiatrists

b proactive

c inter-agency

d provided by specialised regional trauma experts

e sustained for at least two years

\begin{tabular}{|llllllllll||}
\hline MCQ answers & & & & & & \\
1 & & 2 & & 3 & & 4 & & 5 & \\
a & T & a & F & a & F & a & T & a & F \\
b & F & b & T & b & T & b & T & b & T \\
c & T & c & T & c & T & c & F & c & T \\
d & T & d & F & d & F & d & F & d & F \\
e & T & e & F & e & F & e & T & e & T \\
\hline
\end{tabular}

